\title{
Release Kinetics Study of Azithromycin from Bi-layered Tablets
}

\author{
F.M. Shah Noman Ul Bari', Muhammad Rashedul Islam², \\ Md. Mizanur Rahman Moghal ${ }^{3}$ and Israt Jahan Ira ${ }^{1}$ \\ ${ }^{1}$ Department of Pharmacy, Noakhali Science and Technology University, Noakhali-3814, Bangladesh \\ ${ }^{2}$ Department of Pharmaceutical Technology, University of Dhaka, Dhaka-1000, Bangladesh \\ ${ }^{3}$ Department of Pharmacy, Mawlana Bhashani Science and Technology University, Tangail-1902, Bangladesh
}

Received: December 05, 2016; Accepted: December 26, 2016; Published (Web): March 19, 2017

\begin{abstract}
The objective of this study was to analysis in vitro release kinetics of Azithromycin from bi-layer tablets prepared by direct compression using high viscosity to low viscosity grades of hydroxypropyl methyl cellulose (HPMC K15M, HPMC K4M, HPMC $50 \mathrm{cps),} \mathrm{Carbopol} \mathrm{934p} \mathrm{and} \mathrm{Carbopol} \mathrm{974p.} \mathrm{In} \mathrm{addition,} \mathrm{it}$ also includes evaluating the effect of formulation variables like polymer proportion and polymer viscosity on the release of Azithromycin. In vitro release studies were performed using USP Type-II (Rotating paddle method) at $100 \mathrm{rpm}$. The dissolution medium consisted of $0.1 \mathrm{~N} \mathrm{HCl}(900 \mathrm{ml})$ for the first $2 \mathrm{hr}$ and the phosphate buffer ( $\mathrm{pH}$ 6.0) from $3^{\text {rd }}$ to $10^{\text {th }}$ hour. From twenty five different formulations (F-1 to F-25) based on polymer variation, model-dependent and independent methods were used for data analysis and the best results were observed for HPMC 50cps in Korsmeyer- Peppas $\left(\mathrm{R}^{2}=0.995\right.$ on F-23) kinetic model. The release mechanism of all formulations was Fickian.
\end{abstract}

Key words: Azithromycin, Bi-layer tablet, HPMC, Carbopol, Sustained release, Fickian.

\section{Introduction}

Drug release is the process in which drug convert into suitable product form which is subjected to absorption, distribution, metabolism, and excretion (ADME), becoming available for showing Pharmacological activity. Whenever a new solid dosage form is produced, it is necessary to ensure that the new dosage form is shows dissolution in appropriate right manner. Now, a day the Pharmaceutical industries and the registration authorities focus on the drug dissolution/release studies (Paulo, 2001). For the quantitative analysis of drug release of any dosage form it is easier to obtained the correct values by using suitable mathematical formulas as a function of characteristics of some dosage form (Ramteke, 2014). Kinetic models describe the amount of drug dissolved (C) from solid dosage form as a function of test time $t$ or $\mathrm{C}=\mathrm{f}(\mathrm{t})$. Some analytical definitions of the $\mathrm{C}(\mathrm{t})$ are commonly used function, like zero order, first order, Hixson-Crowell, Weibull, Higuchi, Bake-Lonsdale, Korsmeyer-Peppas and Hopfenberg models etc (Hussain, 2013).
In the present study, we were examined bi-layer tablets of Azithromycin, one of the most effective and safe antibiotic useful for treatment of a number of bacterial infections, that is characterized by initial burst drug release in the stomach and complies with the release requirements of sustained-release products. Each of the proposed bi-layer tablets is composed of an immediate-release layer and a sustained-release layer (Bhavesh et al., 2008). Hence, the layered tablets offer a pharmacokinetic advantage over conventional controlled-release dosage forms as the drug is quickly released from the fast-release layer leading to rapid rise of drug plasma concentration followed by continuation of drug release from the sustained release layer (Lopes et al., 2007). This release pattern is required for successful treatment in many therapies, primarily when maximum relief needs to be achieved as soon as possible, and is followed by a sustained-release phase to avoid repeated drug administration (Maggi et al., 1998).

Correspondence to: Muhammad Rashedul Islam, E-mail: rashed1505@yahoo.com 


\section{Materials and Methods}

Materials: For the experiment, Azithromycin was kindly provided by Eskayef Bangladesh Limited as a gift sample. Different grades of HPMC were collected from sole agent Colorcon Limited, India. Microcrystalline Cellulose (Avicel PH 102), Lactose, Carbopol 934P and Carbopol 974P, Providone K 30 and Magnesium stearate were kind gift from Nipa Pharmaceuticals Limited. Potassium dihydrogen phosphate of Merck (Germany), $\mathrm{HCl}$ (37\%) of Merck (Germany) and purified water of Research laboratory (Bangladesh) were used as the reagents. Among the instruments, vernier caliper of Erweka (Germany), Shimadzu UV Spectrophotometer (Japan), hardness tester and dissolution tester were from Erweka (Germany), Pharmatest disintegration tester (Germany), mini drum blender of Cadmach Machinery (India), friability tester of Logan (USA), Hanna $\mathrm{pH}$ meter (Portugal), stainless steel sieve (Bangladesh) and Manesty 16 station compression machine (England) were used.

Preparation of bi-layer tablets of Azithromycin: Preparation of bi-layer tablets of azithromycin was prepared according to previously described procedures (Islam et al., 2016). To evaluate the formulation variables on the release rate of bi-layer tablets of Azithromycin, formulations were prepared by using five different polymers i.e. HPMC K4M (F1 to F5) and HPMC K15M (F6 to F10), Carbopol 934P (F11 to F15), Carbopol 974P (F16 to F20) and HPMC 50cps (F21 to F25), as hydrophilic polymers. All the preparations were then stored in airtight containers at room for further study.

\section{Characterization of release kinetics}

All data obtained from in-vitro release studies were fitted to kinetic equation to find out the mechanism of drug release from the Azithromycin bilayer tablets. In this study, the model dependent approaches included zero order, first order, Higuchi, Korsmeyer-Peppas and Hixson-Crowell were used.

Zero-order model: Drug dissolution from dosage forms that do not disaggregate and release the drug slowly can be represented by the equation:

$$
\mathrm{Q}_{0^{-}} \mathrm{Qt}=\mathrm{K}_{0} \mathrm{t}
$$

Rearrangement of (1) equation yields:

$$
\mathrm{Qt}=\mathrm{Q}_{0}+\mathrm{K}_{0} \mathrm{t} \text {. }
$$

where Qt is the amount of drug dissolved in time t, $\mathrm{Q}_{0}$ is the initial amount of drug in the solution (most times, $\mathrm{Q}_{0}=0$ ) and $\mathrm{K}_{0}$ is the zero order release constant expressed in units of concentration/time. To study the release kinetics, data obtained from in vitro drug release studies were plotted as cumulative amount of drug released versus time (Shaikh et al., 2015)

First order model: This model has also been used to describe absorption and/or elimination of some drugs, although it is difficult to conceptualize this mechanism on a theoretical basis. The release of the drug which followed first order kinetics can be expressed by the equation:

$\mathrm{dC} / \mathrm{dt}=-\mathrm{Kc}$

where $\mathrm{K}$ is first order rate constant expressed in units of time-1.It can be expressed as:

$\log \mathrm{C}=\log \mathrm{C} 0-\mathrm{Kt} / 2.303$

where $\mathrm{C}_{0}$ is the initial concentration of drug, $\mathrm{k}$ is the first order rate constant, and $\mathrm{t}$ is the time (Shaikh et al., 2015). The data obtained are plotted as $\log$ cumulative percentage of drug remaining vs. time which would yield a straight line with a slope of $\mathrm{K} / 2.303$.

Higuchi model: The first example of a mathematical model aimed to describe drug release from a matrix system was proposed by Huguchi in 1961 (Higuchi, 1963). Initially conceived for planar systems, it was then extended to different geometrics and porous systems (Grassi and Grassi, 2005). Accordingly, model expression is given by the equation:

$$
\mathrm{ft}=\mathrm{Q}=\mathrm{A} \sqrt{ } \mathrm{D}(2 \mathrm{C}-\mathrm{Cs}) \mathrm{Cs} \mathrm{t}
$$

where $\mathrm{Q}$ is the amount of drug released in time t per unit area $\mathrm{A}, \mathrm{C}$ is the drug initial concentration, Cs is the drug solubility in the matrix media and D is the diffusivity of the drug molecules (diffusion coefficient) in the matrix substance.

Korsmeyer-Peppas model: Korsmeyer et al. (1983) derived a simple relationship which described drug release from a polymeric system equation. To find out the mechanism of drug release, first $60 \%$ drug release data were fitted in Korsmeyer Peppas model (Korsmeyer et al., 1983). 
$\mathrm{Mt} / \mathrm{M} \infty=\mathrm{K} \mathrm{t}^{\mathrm{n}}$

where $\mathrm{Mt} / \mathrm{M} \infty$ is a fraction of drug released at time $\mathrm{t}, \mathrm{k}$ is the release rate constant and $\mathrm{n}$ is the release exponent. The $\mathrm{n}$ value is used to characterize different release for cylindrical shaped matrices. In this model, the value of $n$ characterizes the release mechanism of drug as described in Table 1. For the case of cylindrical tablets, $0.45 \leq \mathrm{n}$ corresponds to a Fickian diffusion mechanism, $0.45<\mathrm{n}<0.89$ to non-Fickian transport, $\mathrm{n}$ $=0.89$ to Case II (relaxational) transport, and $\mathrm{n}>0.89$ to super case II transport (Riger and Peppas, 1987; Siepmann and Peppas, 2001). To find out the exponent of $n$ the portion of the release curve, where Mt / M $\infty<$ 0.6 should only be used. To study the release kinetics, data obtained from in vitro drug release studies were plotted as log cumulative percentage drug release versus log time.

Hixson and Crowell model: Hixson and Crowell (1931) recognized that the particle's regular area is proportional to the cube root of its volume. They derived the equation:

$$
\mathrm{W}_{0} 1 / 3-\mathrm{Wt} 1 / 3=\kappa \mathrm{t}
$$

where $\mathrm{W}_{0}$ is the initial amount of drug in the pharmaceutical dosage form, $\mathrm{Wt}$ is the remaining amount of drug in the pharmaceutical dosage form at time $\mathrm{t}$ and $\kappa$ (kappa) is a constant incorporating the surface volume relation. The equation describes the release from systems where there is a change in surface area and diameter of particles or tablets (Hixson and Crowell, 1931). To study the release kinetics, data obtained from in vitro drug release studies were plotted as cube root of drug percentage remaining in matrix versus time.

\section{Methods of analysis}

Preparation of dissolution media: A) For preparation of $0.1 \mathrm{~N} \mathrm{HCl}: 11 \mathrm{ml}$ of $35 \%(\mathrm{w} / \mathrm{v}) \mathrm{HCl}$ was taken in a $1000 \mathrm{ml}$ volumetric flask and diluted up to the mark with distilled water. The concentration of this solution was $0.1 \mathrm{~N}$. B) For preparation of phosphate buffer (pH 6.0): First, 6L of 1.0M dibasic sodium phosphate was prepared and taken in a jar. Then it was adjusted with about $40 \mathrm{ml}$ of hydrochloric acid to $\mathrm{pH}$ of $6.0 \pm 0.5$ and mixed.
In vitro dissolution study: The release rate of Azithromycin from tablets was determined using USP Type II (Rotating paddle method) dissolution testing apparatus. The dissolution test was performed using $900 \mathrm{ml}$ of Phosphate buffer $\mathrm{pH} 6.0$ as dissolution medium (according to USP 29), at $37 \pm 0.5^{\circ} \mathrm{C}$ and 100 rpm. A sample $(10 \mathrm{ml})$ of the solution was withdrawn from the dissolution apparatus at predetermined time intervals of $30^{\text {th }} \min , 1^{\text {st }} \mathrm{h}, 2^{\text {nd }} \mathrm{h}, 3^{\text {rd }} \mathrm{h}, 4^{\text {th }}$ hour, $5^{\text {th }} \mathrm{h}, 6^{\text {th }}$ $\mathrm{h}, 7^{\text {th }} \mathrm{h}, 8^{\text {th }} \mathrm{h}, 9^{\text {th }} \mathrm{h}$ and $10^{\text {th }} \mathrm{h}$. The same volume of dissolution medium is replaced to maintain sink condition. Samples withdrawn were filtered through $0.45 \mu \mathrm{m}$ membrane filter and suitably diluted with Phosphate buffer. Absorbance of these solutions was measured at $226 \mathrm{~nm}$ using a UV-1800 SHIMADZU spectrophotometer. The release studies were conducted in triplicate (6 tablets in each set). Cumulative percentage of drug release was calculated using an equation obtained from a standard curve. Dissolution rate was studied for all designed formulation.

Statistical analysis: One-way analysis of variance (ANOVA) (performed at 5\% significance level using SPSS Version 16.0) were used to compare the difference of dissolution profiles of the Azithromycin bilayer tablets.

\section{Results and Discussion}

In the present study, bi-layer tablets of Azithromycin were prepared by using different polymers like HPMC K4M, HPMC K15M, Carbopol 934P, Carbopol 974P and HPMC 50cps as hydrophilic polymers, at the concentration of $5.55 \%, 6.66 \%, 7.77 \%$, $8.88 \%$ and $10 \%$ as rate retarding agent, povidone K30 as binding agent and microcrystalline cellulose as diluent as well as disintegrating agent.

In vitro release rate: The in vitro release is depending upon the nature of drug, nature of polymer, drug to polymer ratio and the medium used. In order to examine the effect of polymer reaction (concentration $\&$ ratio) on the matrix tablets, we have used six different polymers i.e, HPMC K4M, \& HPMC K15M, Carbopol 934P, Carbopol 947P and HPMC 50cps in this study and so, their individual drug release profile were evaluatedto analyze the type of polymers which influences the drug release patterns. Highest release of 
Azithromycin was from F-21 as it contained $50 \mathrm{mg}$ of HPMC 50cps with drug polymer ratio 1:0.07 and methyl cellulose $60 \mathrm{mg}$. Slowest release was found from F-20 which contained 90mg of Carbopol 974P with drug polymer ratio 1:0.14 with methyl cellulose 20 $\mathrm{mg}$.So, drug release retardation is directly proportional to the concentration of the polymer and inversely proportional with methyl cellulose. From the previous study, we also found that Carbopol polymer shows greater and reliable drug retardation ability compared to HPMC polymer (Islam et al., 2016). .

In vitro release kinetics: From all of the first five formulations best fitted with the Korsmeyer-Peppas model then others four model. In that case, the value for $\mathrm{n}$ for Korsmeyer-Peppas release is in range 0.5 which indicates that the drug was released by Fickian transport.

For the formulation F-1 to F-5, F-1 best fit with the Korsmeyer-Peppas $\left(\mathrm{R}^{2}=0.937\right)$ model (Figure 4) to some extent and then First order model $\left(R^{2}=0.012\right)$ which shown in figure 2 and then with Higuchi (Figure 3 ) and Hixon-Crowell model (Figure 5). The release of Azithromycin was dependent on the concentration of the drug in the depot, Fickian diffusion through a porous matrix (Figure 1).

From figures 6 to 10 for formulation F-6 to F-10,F6 best fit Korsmeyer-Peppas $\left(\mathrm{R}^{2}=0.974\right)$ which shown in figure 9 and then First order $\left(\mathrm{R}^{2}=0.253\right)$ and Higuchi $\left(\mathrm{R}^{2}=0.819\right)$ kinetic model (Figures 7 and 8). Drug release dependent on concentration from the depot, Fickian diffusion transport.

Release kinetic studies for the formulation F-11 to F-15 which shown in figures 11 to 15 , we observed that F-11, F-12, F-13, F-14 and F-15 best fit with Korsmeyer-Peppas $\quad\left(\mathrm{R}^{2}=0.900, \quad \mathrm{R}^{2}=0.882, \mathrm{R}^{2}=0.940\right.$, $\mathrm{R}^{2}=0.971$ and $\mathrm{R}^{2}=0.992$ respectively) kinetic model to some extent and then First order $\left(R^{2}=0.006, R^{2}=0.001\right.$, $\mathrm{R}^{2}=0.014, \mathrm{R}^{2}=0.017$ and $\left.\mathrm{R}^{2}=0.013\right)$ and Higuchi $\left(\mathrm{R}^{2}=0.841, \quad \mathrm{R}^{2}=0.779, \quad \mathrm{R}^{2}=0.722, \quad \mathrm{R}^{2}=0.729 \quad\right.$ and $\left.\mathrm{R}^{2}=0.805\right)$ kinetic model.

As shown in figures from 16 to 20 , the release rate of F-16, F-17, F-19 and F-20 best fit with KorsmeyerPeppas $\left(\mathrm{R}^{2}=0.975, \mathrm{R}^{2}=0.989, \mathrm{R}^{2}=0.916\right.$ and $\mathrm{R}^{2}=0.937$ respectively) model and then first order $\left(R^{2}=0.288\right.$, $\mathrm{R}^{2}=0.137, \mathrm{R}^{2}=0.004$ and $\left.\mathrm{R}^{2}=0.004\right)$ whereas $\mathrm{F}-18$ best fit with first order $\left(\mathrm{R}^{2}=0.078\right)$ and then Hixon-Crowell $\left(\mathrm{R}^{2}=0.094\right)$ and Higuchi $\left(\mathrm{R}^{2}=0.881\right)$ kinetic model. The release of drug from F-18 follows concentration dependent anomalous transport (Diffusion and Erosion)

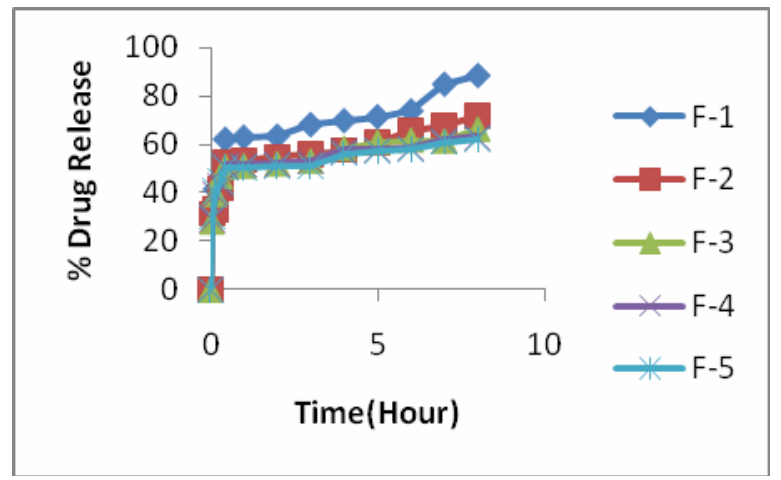

Figure 1. Zero Order Plots of Release Kinetics of Azithromycin from HPMC K4M based tablets of F-1 to F-5.

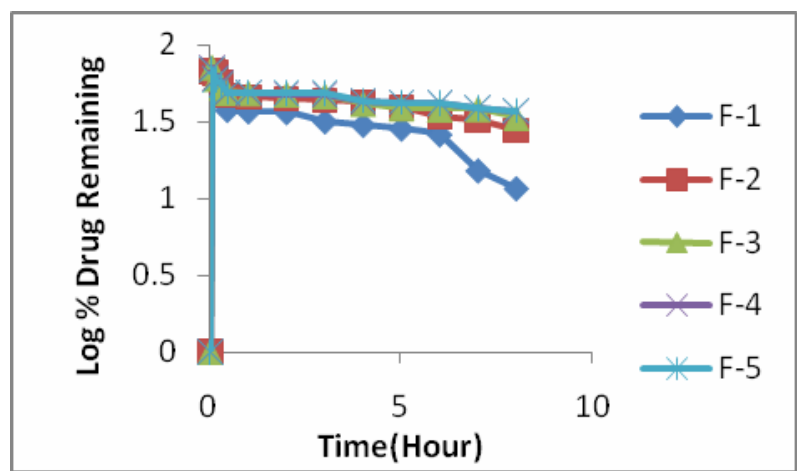

Figure 2. First Order Plots of Release Kinetics of Azithromycin from HPMC K4M based tablets of F-1 to F-5.

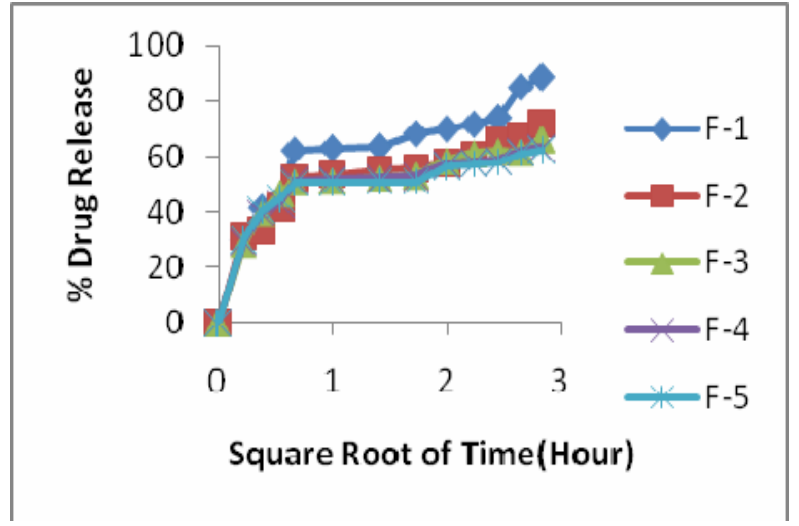

Figure 3. Higuchi plots of Release Kinetics of Azithromycin from HPMC K4M based tablets of F-1 to F-5. 
Table 1. Formulation of Azithromycin Bi-layered tablets based on different polymers.

\begin{tabular}{|c|c|c|c|c|c|c|c|c|c|c|c|}
\hline \multirow{2}{*}{$\begin{array}{l}\text { Formu } \\
\text { lation } \\
\text { code }\end{array}$} & \multicolumn{10}{|c|}{ Ingredients (mg/tab) } & \multirow[b]{2}{*}{$\begin{array}{c}\text { Total } \\
\text { tab wt }\end{array}$} \\
\hline & $\begin{array}{c}\text { Azithro- } \\
\text { mycin }\end{array}$ & $\begin{array}{c}\text { HPMC } \\
\text { K4M }\end{array}$ & $\begin{array}{l}\text { HPMC } \\
\text { K15M }\end{array}$ & $\begin{array}{l}\text { Carbo- } \\
\text { pol } \\
934 \mathrm{p}\end{array}$ & $\begin{array}{c}\text { Carbo- } \\
\text { pol } \\
974 \mathrm{p}\end{array}$ & $\begin{array}{c}\text { HPMC } \\
50 \mathrm{cps}\end{array}$ & $\begin{array}{l}\text { Micro } \\
\text { Crystalline } \\
\text { cellulose }\end{array}$ & $\begin{array}{c}\text { Provi- } \\
\text { done } \\
\text { K30 }\end{array}$ & $\begin{array}{c}\mathrm{Mg} \\
\text { Stearate }\end{array}$ & talc & \\
\hline F1 & 250 & 50 & 0 & 0 & 0 & 0 & 60 & 9 & 2.5 & 3.5 & 375 \\
\hline F2 & 250 & 60 & 0 & 0 & 0 & 0 & 50 & 9 & 2.5 & 3.5 & 375 \\
\hline F3 & 250 & 70 & 0 & 0 & 0 & 0 & 40 & 9 & 2.5 & 3.5 & 375 \\
\hline F4 & 250 & 80 & 0 & 0 & 0 & 0 & 30 & 9 & 2.5 & 3.5 & 375 \\
\hline F5 & 250 & 90 & 0 & 0 & 0 & 0 & 20 & 9 & 2.5 & 3.5 & 375 \\
\hline F6 & 250 & 0 & 50 & 0 & 0 & 0 & 60 & 9 & 2.5 & 3.5 & 375 \\
\hline F7 & 250 & 0 & 60 & 0 & 0 & 0 & 50 & 9 & 2.5 & 3.5 & 375 \\
\hline F8 & 250 & 0 & 70 & 0 & 0 & 0 & 40 & 9 & 2.5 & 3.5 & 375 \\
\hline F9 & 250 & 0 & 80 & 0 & 0 & 0 & 30 & 9 & 2.5 & 3.5 & 375 \\
\hline F10 & 250 & 0 & 90 & 0 & 0 & 0 & 20 & 9 & 2.5 & 3.5 & 375 \\
\hline F11 & 250 & 0 & 0 & 50 & 0 & 0 & 60 & 9 & 2.5 & 3.5 & 375 \\
\hline F12 & 250 & 0 & 0 & 60 & 0 & 0 & 50 & 9 & 2.5 & 3.5 & 375 \\
\hline $\mathrm{F} 13$ & 250 & 0 & 0 & 70 & 0 & 0 & 40 & 9 & 2.5 & 3.5 & 375 \\
\hline F14 & 250 & 0 & 0 & 80 & 0 & 0 & 30 & 9 & 2.5 & 3.5 & 375 \\
\hline F15 & 250 & 0 & 0 & 90 & 0 & 0 & 20 & 9 & 2.5 & 3.5 & 375 \\
\hline F16 & 250 & 0 & 0 & 0 & 50 & 0 & 60 & 9 & 2.5 & 3.5 & 375 \\
\hline F17 & 250 & 0 & 0 & 0 & 60 & 0 & 50 & 9 & 2.5 & 3.5 & 375 \\
\hline F18 & 250 & 0 & 0 & 0 & 70 & 0 & 40 & 9 & 2.5 & 3.5 & 375 \\
\hline F19 & 250 & 0 & 0 & 0 & 80 & 0 & 30 & 9 & 2.5 & 3.5 & 375 \\
\hline F20 & 250 & 0 & 0 & 0 & 90 & 0 & 20 & 9 & 2.5 & 3.5 & 375 \\
\hline F21 & 250 & 0 & 0 & 0 & 0 & 50 & 60 & 9 & 2.5 & 3.5 & 375 \\
\hline $\mathrm{F} 22$ & 250 & 0 & 0 & 0 & 0 & 60 & 50 & 9 & 2.5 & 3.5 & 375 \\
\hline $\mathrm{F} 23$ & 250 & 0 & 0 & 0 & 0 & 70 & 40 & 9 & 2.5 & 3.5 & 375 \\
\hline F24 & 250 & 0 & 0 & 0 & 0 & 80 & 30 & 9 & 2.5 & 3.5 & 375 \\
\hline F25 & 250 & 0 & 0 & 0 & 0 & 90 & 20 & 9 & 2.5 & 3.5 & 375 \\
\hline
\end{tabular}

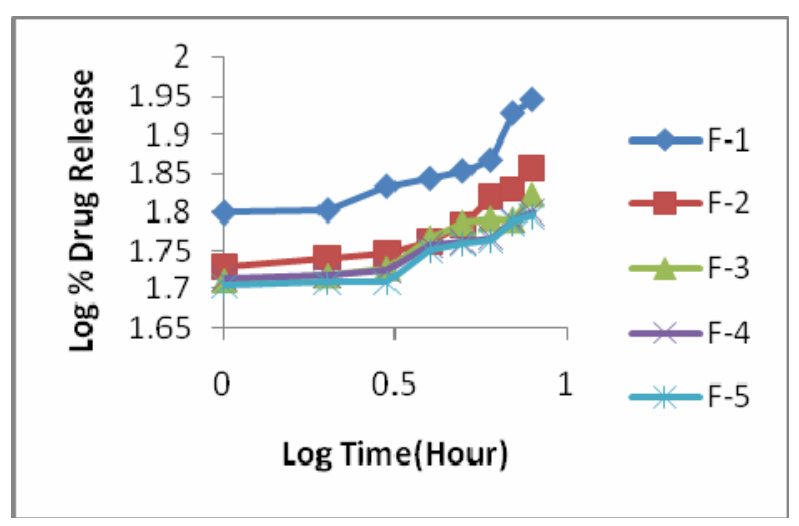

Figure 4. Korsmeyer-PeppasPlots of Release Kinetics of Azithromycin K4M based tablets of F-1 to F-5.

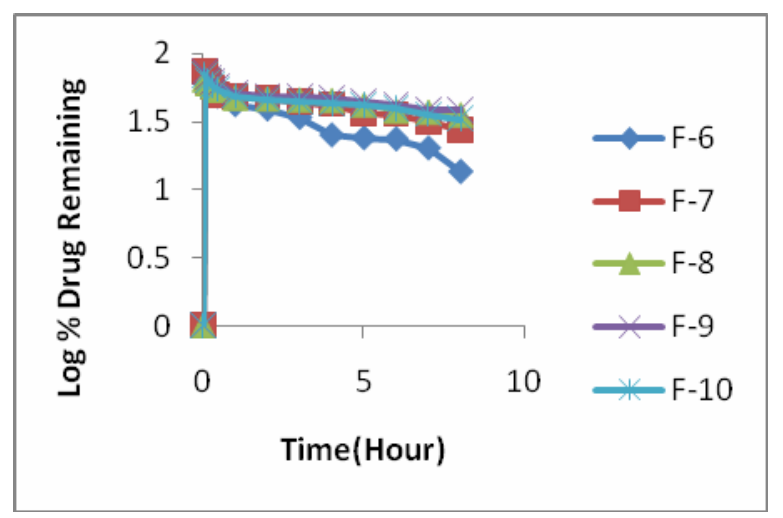

Figure 5. Hixson-Crowell Plots of Release Kinetics of Azithromycin from HPMC K4M based tablets of F-1 to F-5. 


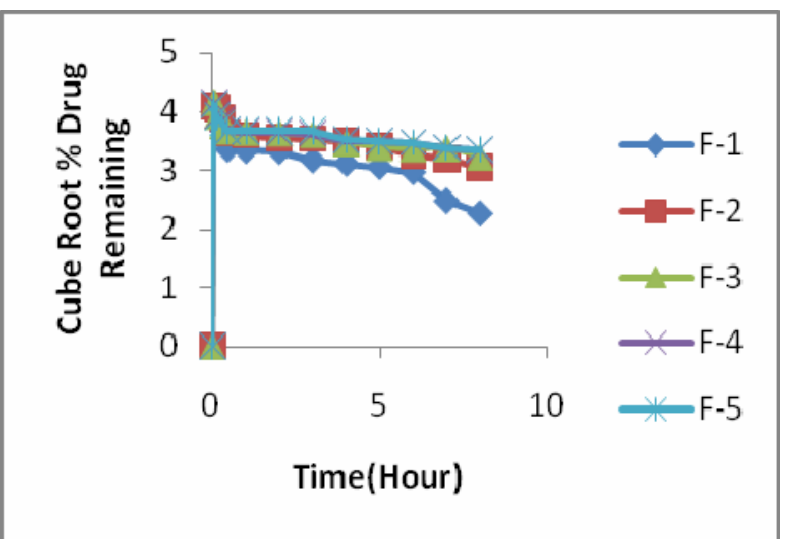

Figure 6. Zero Order Plots of Release Kinetics of Azithromycin from HPMC K15M based tablets of F-6 to F-10.

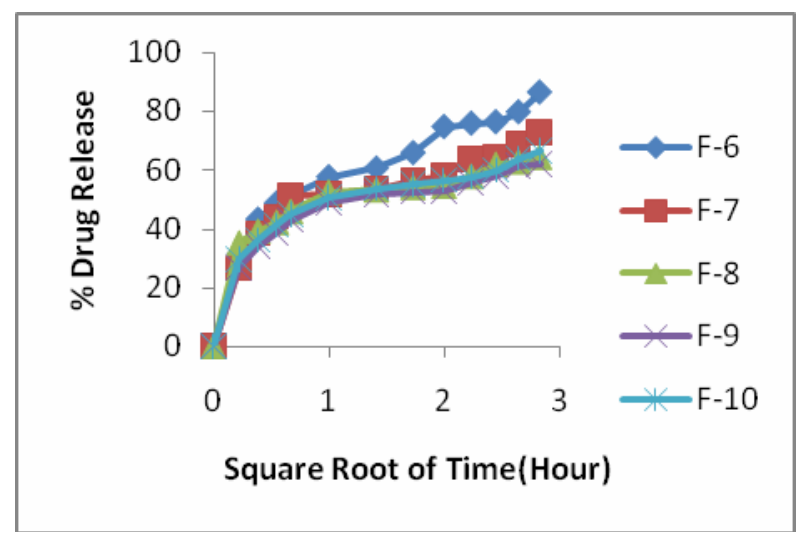

Figure 7. First Order Plots of Release Kinetics of Azithromycin from HPMC K15M based tablets of F-6 to F-10.

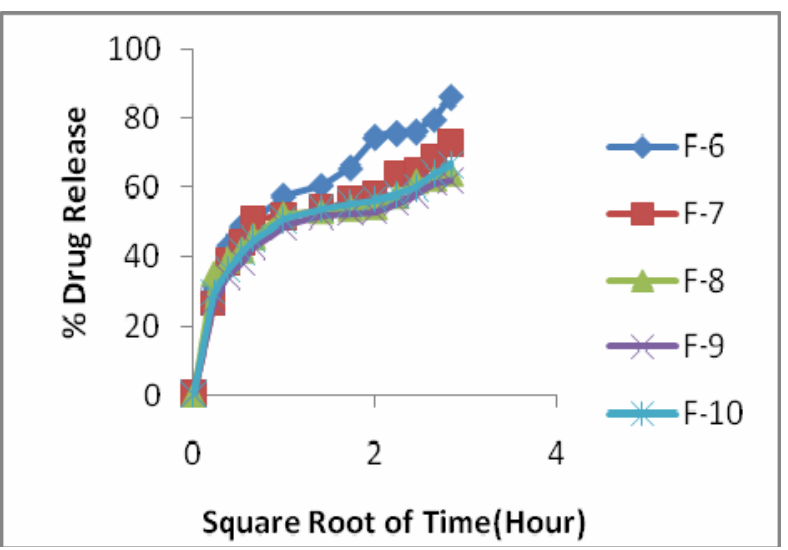

Figure 8. Higuchi Plots of Release Kinetics of Azithromycin from HPMC K15M based tablets of F-6 to F-10.

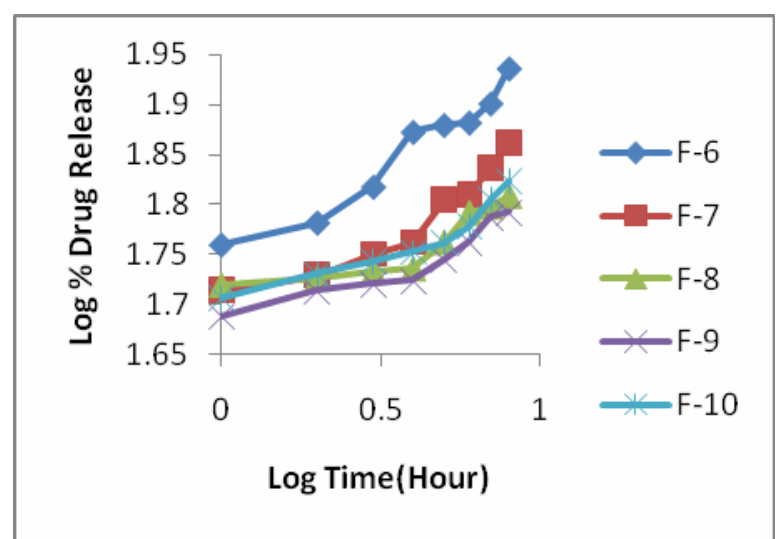

Figure 9. Korsmeyer-Peppas Plots of Release Kinetics of Azithromycin from HPMC K15M based tablets of F-6 to F-10.

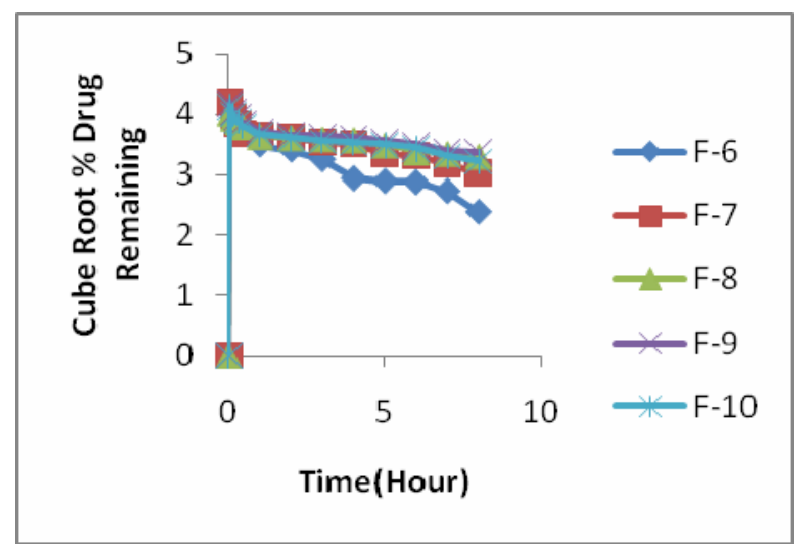

Figure 10. Hixson-Crowell Plots of Release Kinetics of Azithromycin from HPMC K15M based tablets of F-6 to F-10.

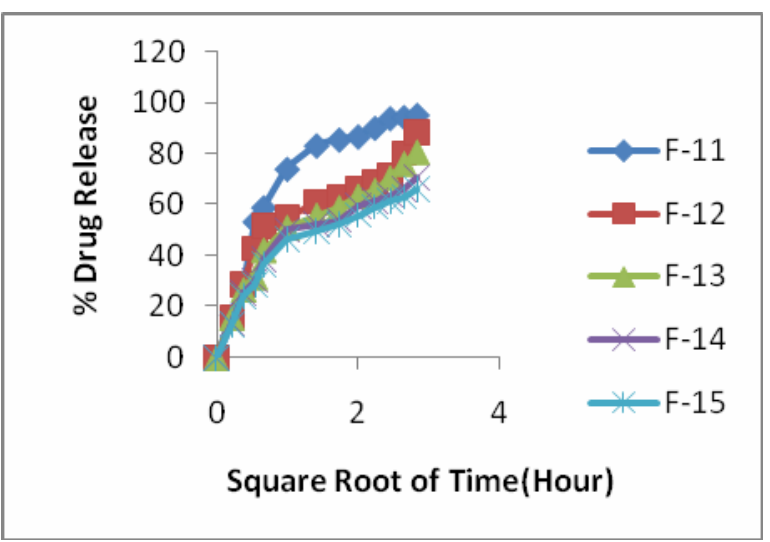

Figure 11. Zero Order Plots of Release Kinetics of Azithromycin from Carbopol 934P based Azithromycin Bi-layer Tablets of F-11 to F-15 


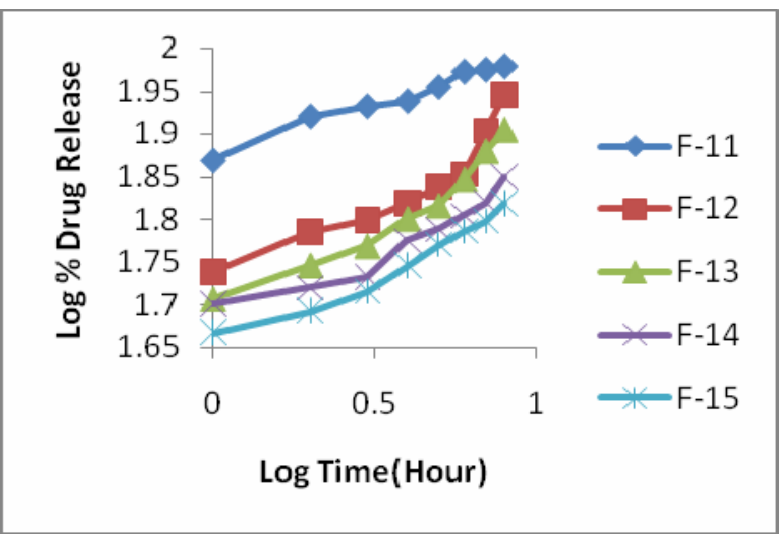

Figure 12. First Order Plots of Release Kinetics of Azithromycin from Carbopol 934P based Azithromycin Bi-layer Tablets of F-11 to F-15.

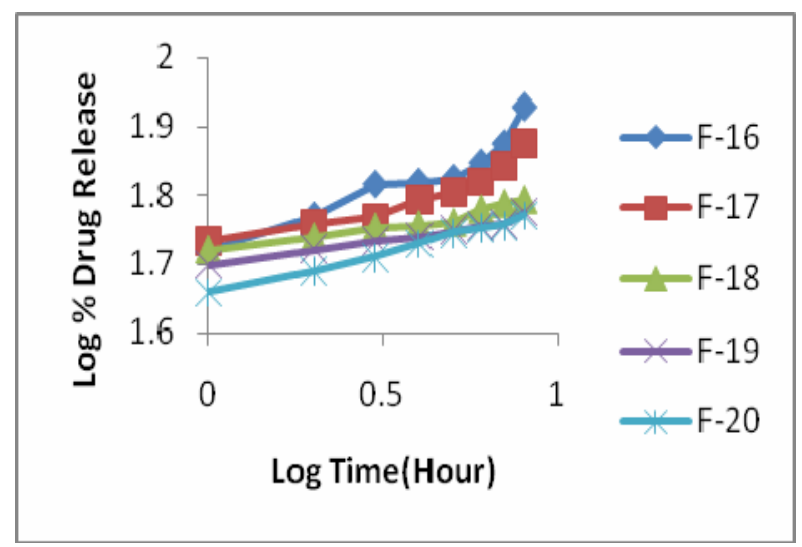

Figure 13. Higuchi Plots of Release Kinetics of Azithromycin from Carbopol 934P based tablets of F-11 to F-15.

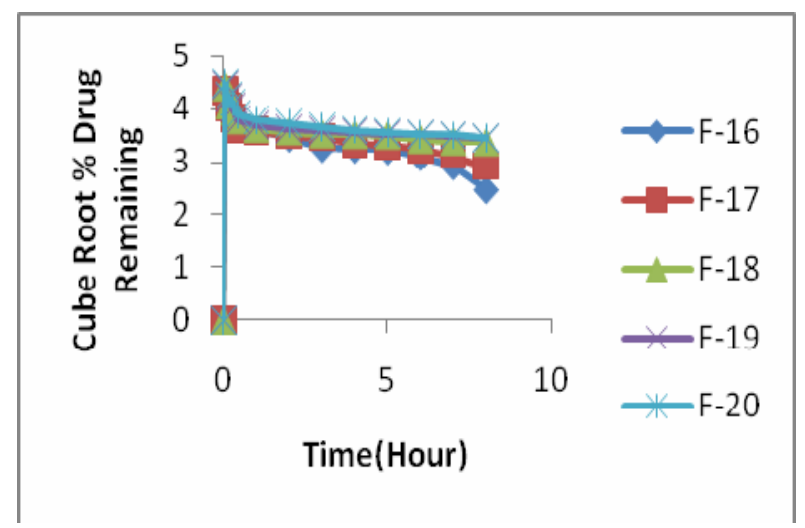

Figure 14. Korsmeyer-PeppasPlots of Release Kinetics of Azithromycin from Carbopol 934P based tablets of F-11 to F15 .

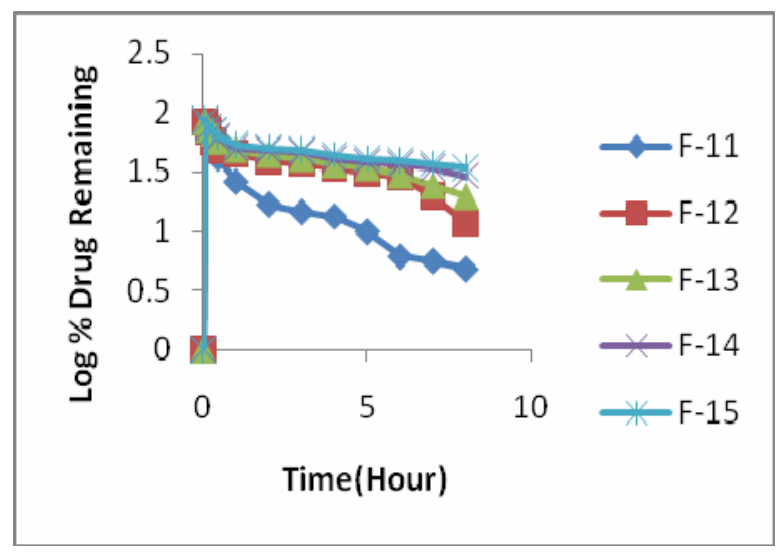

Figure 15. Hixson-Crowell Plots of Release Kinetics of Azithromycin from Carbopol 934P based tablets of F-16 to F-20.

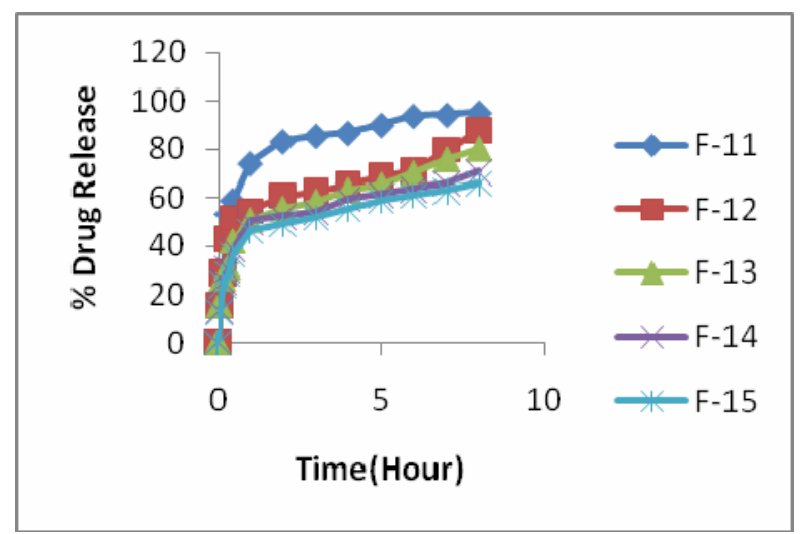

Figure 16. Zero Order Plots of Release Kinetics of Azithromycin from Carbopol974P based tablets of F-16 to F-20.

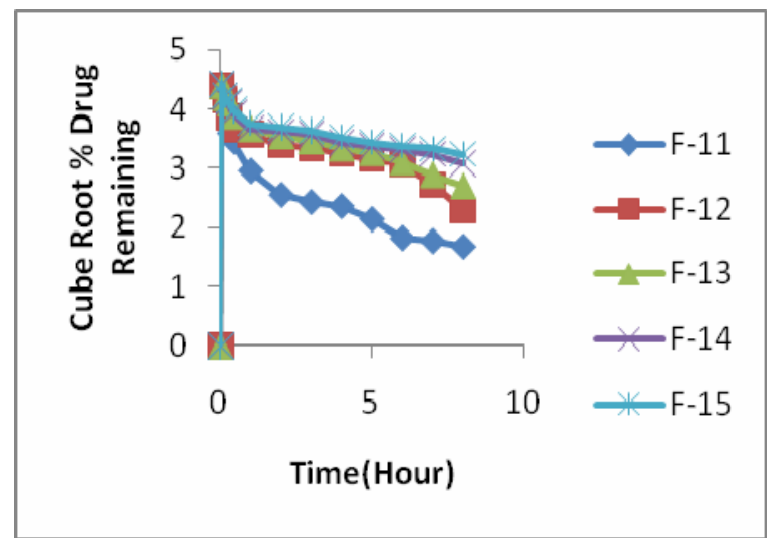

Figure 17. First Order Plots of Release Kinetics of Azithromycin from Carbopol 974P based tablets of F-16 to F-20. 


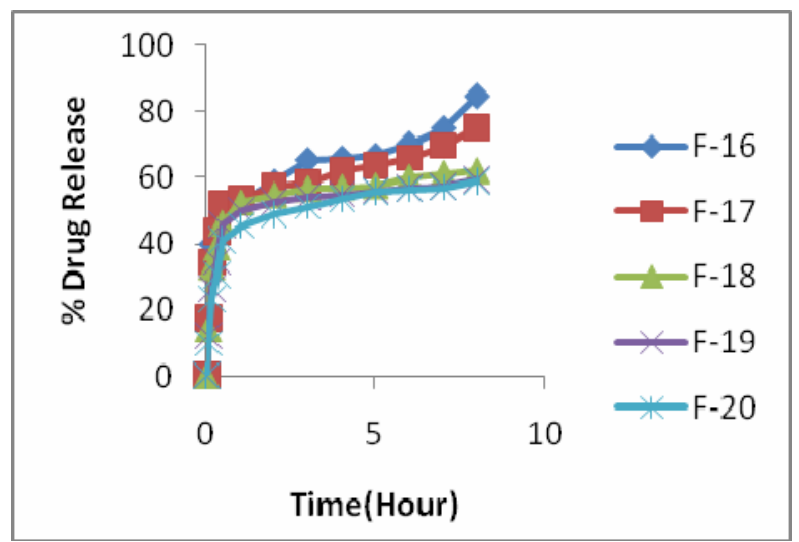

Figure 18. Higuchi Plots of Release Kinetics of Azithromycin from Carbopol 974P based tablets of F-16 to F-20.

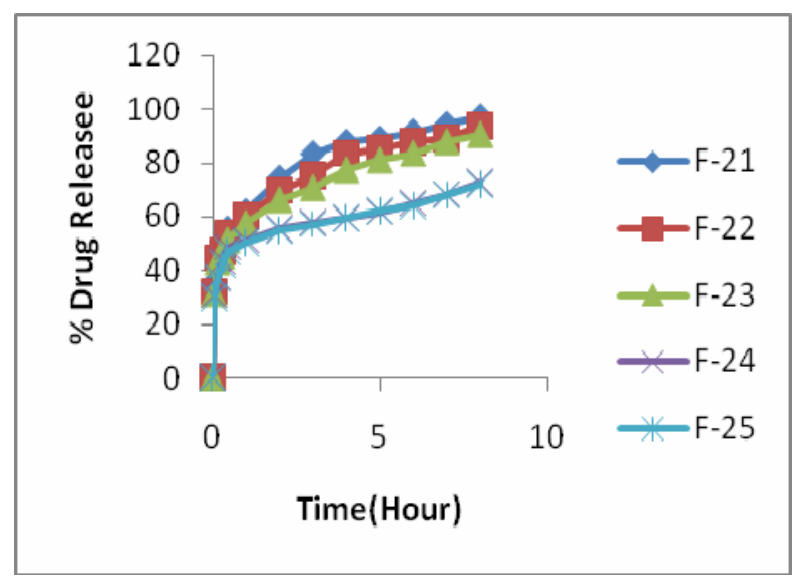

Figure 19. Korsmeyer-PeppasPlots of Release Kinetics of Azithromycin from Carbopo1974P based tablets of F-16 to F-20.

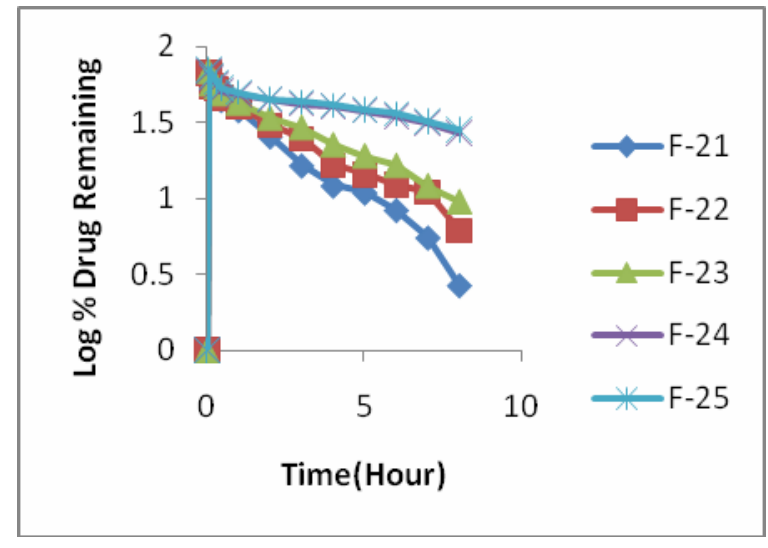

Figure 20. Hixson-Crowell Plots of Release Kinetics of Azithromycin from Carbopol 974P based tablets of F-16 to F-20.

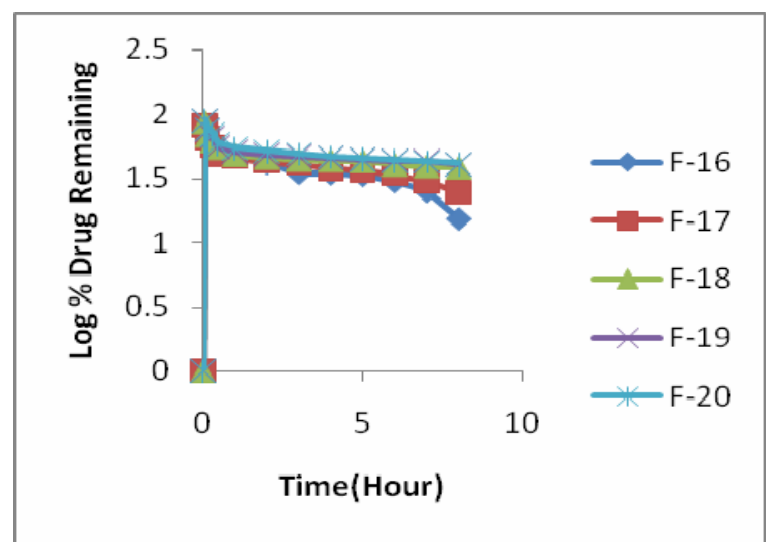

Figure 21. Zero Order Plots of Release Kinetics of Azithromycin from HPMC 50cps based tablets of F-21 to F-25.

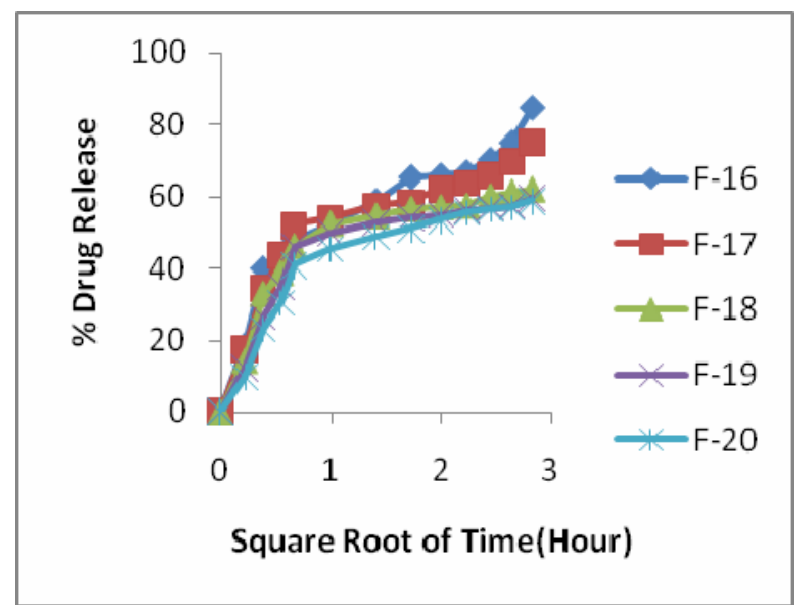

Figure 22. First Order Plots of Release Kinetics of Azithromycin from HPMC 50cps based Tablets of F-21 to F-25.

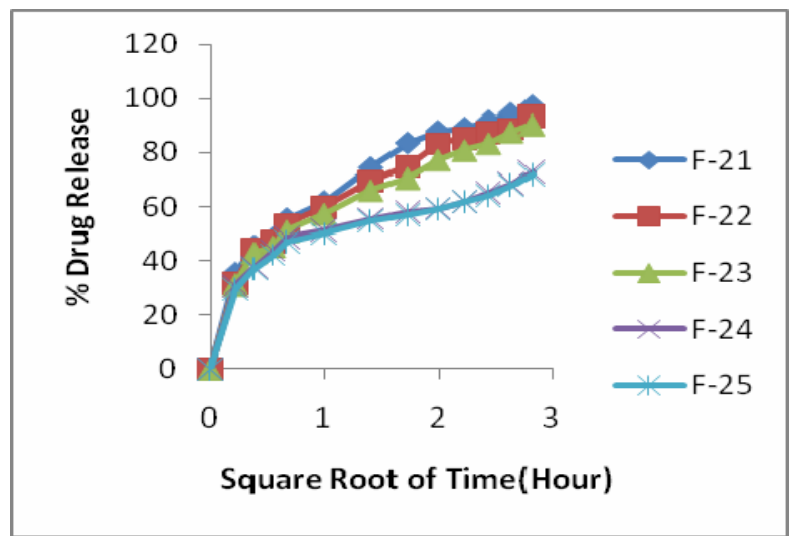

Figure 23. Higuchi Plots of Release Kinetics of Azithromycin from HPMC 50cps based Tablets of F-21 to F-25. 


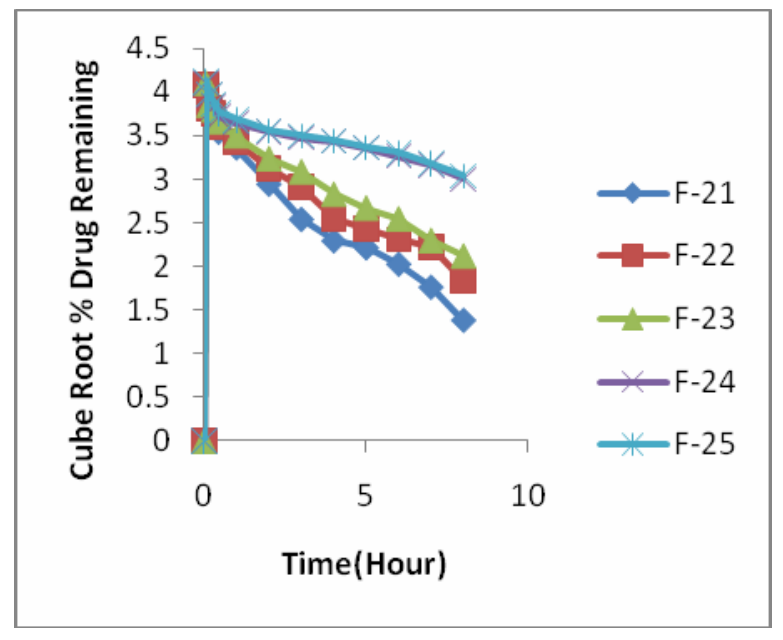

Figure 24. Korsmeyer-Peppas Plots of Release Kinetics of Azithromycin from HPMC 50cps based tablets of F-21 to F-25

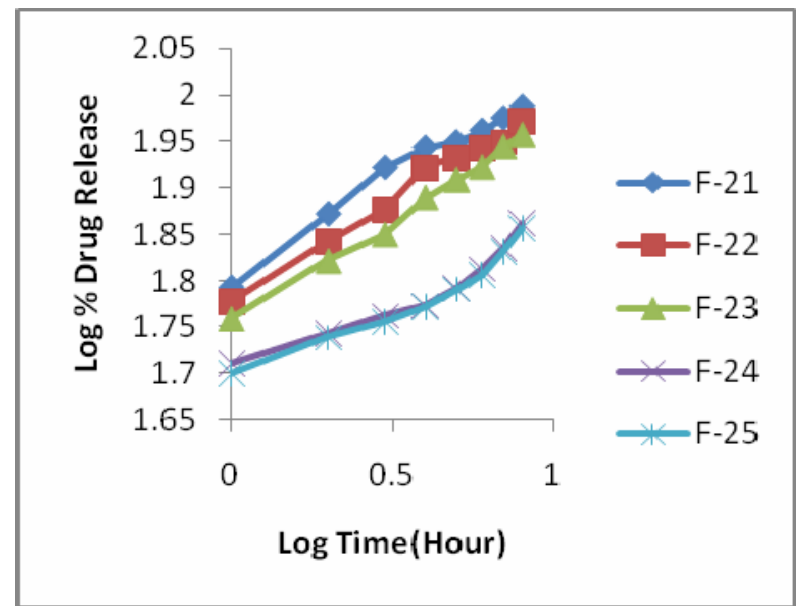

Figure 25. Hixson-Crowell Plots of Release Kinetics of Azithromycin from HPMC 50cps based tablets of F-21 to F-25

Finally, figures 24 shows that formulation F-21, F22, F-24 and F-25 best fit with Korsmeyer-Peppas $\left(\mathrm{R}^{2}=0.983, \quad \mathrm{R}^{2}=0.970, \quad \mathrm{R}^{2}=0.844 \quad\right.$ and $\quad \mathrm{R}^{2}=0.823$ respectively) model, whereas figure 22 shows F-23 best fit with first order $\left(\mathrm{R}^{2}=0.040\right)$ and then Hixon-Crowell $\left(\mathrm{R}^{2}=0.057\right)$ and Higuchi $\left(\mathrm{R}^{2}=0.827\right)$ kinetic model which shown in figures 25 and 23 , respectively. The release of drug from F-23 follows concentration dependent anomalous transport (Diffusion and Erosion) (Figure 21).

\section{Conclusion}

The study develops new sustained formulation of Azithromycin by using different types of HPMC (HPMC K4M, HPMC K15M andHPMC 50cps) and Carbopol (934P and 974P) to evaluate the effect of HPMC and Carbopol as rate controlling polymer. Invitro release profile of Azithromycin was analyzed on the basis of various mathematical models such as zero order, first order, Higuchi, Korsmeyer-Peppas and Hixon-Crowell kinetic model.Further study may be conducted by formulating new formulation with the combination of polymers of HPMC and carbopol to evaluate the combination efficacy of both polymers.After this study a further pharmacological study on living animal will be very helpful to determine the side effects and adverse effect and dose interval of this new type of formulation. So, the next step of this study will be the pharmacological evaluation and stability study of the formulations that are given good results in this study.

\section{References}

Bhavesh, S., Suresh, G. and Sanjay, S. 2008. Formulation and evaluation of bilayer tablet of Metoclopramide hydrochloride and Ibuprofen. AAPS. Pharma. Sci. Tech. 9, 818-827.

Grassi, M. and Grassi, G. 2005. Mathematical modelling and controlled drug delivery: matrix systems. Curr. Drug Deliv. 2, 97-116.

Hussain, L. 2013. Kinetic modeling and dissolution profiles comparison: An overview, Int .J. Pharm. Bio. Sci. 4, 728-737.

Hixson, A.W. and Crowell, J.H. 1931. Dependence of reaction velocity upon surface and agitation. Ind. Eng. Chem. 23. 1160-1168.

Higuchi,T. 1963. Mechanism of sustained-action medication, theoretical analysis of rate of release of solid drugs dispersed in solid matrices. J. Pharm. Sci. 52, 52. 32.

Islam, M.R., Moghal, M.R., Noman Ul Bari, F.M. and Mamun, E.A. 2016. Design and development of bilayered sustained release Azithromycin tablets. DU. J. Pharm. Sci. 15, 227-234.

Korsmeyer, R. W., Gurny, R., Doelker, E., Buri, P. and Peppas, N. A. 1983. Mechanisms of solute release from porous hydrophilic polymers. Int. J. Pharm, 15, 25-35

Lopes, C.M., José, M., Lobo, S., Pinto, F. and Costa, P.C. 2007. Compressed matrix core tablet as a quick/slow dual-component delivery system containing Ibuprofen, AAPS. Pharm. Sci. Tech. 8, 76-78. 
Maggi, L., Machiste, E.O., Torre, M.L. and Conte, U. 1998. Formulation of biphasic release tablets containing slightly soluble drugs. Eur. J. Pharm. Biopharm. 48, 37- 42.

Paulo, C. 2001. Modelling and comparison of dissolution profile. Eur. J. Phar. Sci. 13, 123-133.

Ramteke, K. 2014. Mathematical models of drug dissolution: a review. Sch. Acad. J. Pharm. 3, 388-396.
Ritger, P.L. and Peppas, N.A. 1987. A simple equation for description of solute release II. Fickian and anomalous release from swellable devices. J. Control. Rel. 5, 37-42.

Shaikh, H.K., Kshirsagar, R.V. and Patil, S.G. 2015. Mathematical models for drug release characterization: a review. W. J. P. Pharm. Sci. 4, 324-338.

Siepmann, J. and Peppas, N.A. 2001. Modeling of drug release from delivery systems based on hydroxypropyl methyl cellulose (HPMC). Adv. Drug Deliv. Rev.48, 139157. 